\title{
Counteracting Educational Injustice With Applied Critical Leadership: Culturally Responsive Practices Promoting Sustainable Change
}

\author{
Lorri J. Santamaría \\ The University of Auckland \\ New Zealand \\ Andrés P. Santamaría \\ AUT University \\ New Zealand
}

ABSTRACT: This contribution considers educational leadership practice to promote and sustain diversity. Comparative case studies are presented featuring educational leaders in the United States and New Zealand who counter injustice in their practice. The leaders' leadership practices responsive to the diversity presented in their schools offer reconceptualizations of educational leadership for a changing society. Applied critical leaders are defined through similarities and differences, followed by suggestions for critical leadership promoting social justice and educational equity and culturally responsive practices to inform policy and practice for sustainable future-focused educational leadership.

KEY WORDS: educational leadership, diversity, case study, New Zealand, United States

Context, Purpose, and Central Thesis

Conceptual Framework and Literature Review

Methodological Approach

Findings

Discussion and Implications

Conclusion

References

In this article, we present an argument regarding the contexts and relative strengths of the leadership practices of individuals who work in the field of educational leadership for diversity, social justice, and equity. This study serves to engage dialogue while providing a platform to explore the intersectional, crosscultural, and collaborative elements underlying applied critical leadership. Applied critical leadership (ACL) offers an example of culturally responsive leadership in education where the practice is drawn from positive attributes of a leader's identity (Santamaría \& Santamaría, 2012). The questions that focus this inquiry include: "In what ways do the ACL leadership practices of Indigenous leaders, leaders of color, and leaders who 'choose' to lead through critical lenses intersect and manifest as culturally responsive leadership contributing to sustainable change?" How might these intersections be conceptualized? What are the implications for educational leadership preparation, policy, and reform? 


\section{Context, Purpose, and Central Thesis}

Research findings suggest that students from historically dominant and usually wealthier backgrounds continue to outperform Indigenous students and students of color who are also disproportionately poor (Kirsch et al., 2002). This is the case internationally, despite educational research and professional development efforts that have identified disparities and inequities in schooling from early childhood educational settings to tertiary education at universities. Responding to pervasive educational inequality trends, this article features culturally responsive educational leadership in New Zealand and the United States to build on and expand current multicultural educational research based on educational practices in Aotearoa, NZ (Bishop, Berryman, Cavanagh, \& Teddy, 2009; May \& Sleeter, 2010). Using data gleaned from a comparative multiple case study, we argue that these rapidly changing demographics in the United States, Australasia, and similar countries demand innovative, complex, visionary, collaborative, culturally grounded, and immanently future-focused leadership practices. These new ways of thinking about and applying educational leadership offer a departure from hegemonic conceptualizations of what it means to lead in educational contexts (Bogotch, 2002; Brooks \& Normore, 2010; Young \& Brooks, 2008).

Related research suggests that leadership in the new century needs to come from the experience and knowledge base of the largest number of people in many parts of the United States and many parts of the world: Indigenous people and people of color (Bishop et al., 2009; Horsford, 2010, 2011; Santamaría, Santamaría, Webber, \& Pearson, 2014). This inquiry provides an example of a critical research-to-practice perspective to benefit teachers, policymakers, scholars, and students of education and educational leadership in national and global arenas. This contribution underscores the notion that educational leadership is an interdisciplinary, dynamic, multidimensional process that is context embedded and specific to people, places, and time. Leadership in culturally and linguistically diverse settings often operates differently and independent of managerial functions and traditional conceptualizations of educational leadership found in frequently cited literature (e.g., Hargreaves \& Fink, 2004; Leithwood \& Poplin, 1992). In more diverse contexts, we have observed emergent new ways of leading that are responsive to socio-political realities and serve to benefit larger numbers of learners as well as those students who have been systemically underserved over time (Santamaría, 2014). By making these implicit leadership practices explicit, this article aims to inform educational practitioners who are navigating the challenges and opportunities afforded by diversity in education. This work complements existing educational leadership research by offering examples of different leadership approaches and perspectives to the current discourse on educational leadership, including futurefocused guidelines and implications for research and practice. 


\section{Conceptual Framework and Literature Review}

We first offer an analysis of relevant literature and a comparative multiple case study developed from the composite accounts of over 20 leaders to support a dynamic, complex, and evolving definition for educational leadership. Findings include practices that are applied, critical, Indigenous, of and by peoples of color. We expand similar comparative educational leadership work in international contexts with a case study approach juxtaposing extant data from the US with newly collected data from NZ (Dimmock \& Walker, 2002). The NZ and US leaders presented in the case study were selected to participate because they had been observed to actively promote social justice indicative of a changing global educational landscape. We also capture and conceptualize the ways in which educational leaders from systemically underserved backgrounds (e.g., Latino/a, Māori, African American) practice ACL in a concerted effort to identify ways in which leaders' shared oppressions -experienced or identified-- might be considered as valuable resources in addressing, interrupting, and reversing educational inequities in the US and similar countries throughout the world.

\section{Educational Leadership and Demographic Change}

Educational leadership as a field and discipline has been slow to respond to the realities of increased racial, ethnic, cultural and linguistic diversity and their intersectional implications on social justice at various levels of education (Theoharis, 2007). In this regard it has been and remains a field skeptical of the consequences of difference. Leadership and management as a result are largely 'colorblind' in approach leaving critical theorists and pedagogues with the responsibility of raising classroom teachers' and practitioners' awareness of multicultural education and cultural responsiveness. The few interdisciplinary scholars who engage in educational leadership and more critical intersecting fields of study remain on the margins of educational leadership reform (Brooks, 2008; Normore, 2008; Horsford, 2010; Jean-Marie, Normore, \& Brooks, 2009; Santamaría \& Santamaría, 2012). Yet, even with seemingly global understandings that build from Indigenous and culturally/linguistically diverse learners' 'funds of knowledge' (Moll, Amanti, Neff, \& Gonzalez, 1992), realms of experience (Bishop, 1996), and the meeting of students' most basic needs prior to instruction (Duncan-Andrade, 2009; Maslow, 1943), larger numbers of historically underserved students the world over experience increasing educational inequities ranging from low academic performance to high push-out rates, resulting in a lack of education, diminished well-being, and futures laden with even greater inequities.

Educational leadership for social justice is trending at the moment (Mansfield, 2014). Research in the discipline by Indigenous researchers and scholars of color agree that ethnic and racial identity play major roles in the ways 
in which educational leadership is practiced (Lomotey, 1987; MurakamiRamalho, Nuñez, \& Cuero, 2010; Santamaría \& Santamaría, 2012; Santamaría et al., 2014). These researchers and others suggest that culturally responsive leadership may result in socially just and equitable outcomes for all learners in contexts where disparities are present (Gooden \& Dantley, 2012; Horsford, 2011; Jean-Marie, 2008; Khalifa, 2012; Santamaría, 2014; Tillman, 2008). Many of these academics research and publish together as well as present papers at conferences in symposia, making major contributions to the field by providing innovative ways to think about leadership from a variety of worldviews. Similarly, White scholars on educational leadership for social justice have provided insight from their perspectives on ways to approach inequities germane to past and present demographic shifts in the US (e.g., Brooks, 2008; Normore, 2008; Shields, 2010; Theoharis, 2007; Young \& Brooks, 2008). Some White scholars of educational leadership who promote social justice and equity tend to publicly 'walk the talk.' For example, a few have been known to partner or collaborate with academics of color in the discipline or edit book series or special issues that feature a multicultural group of scholars around similar critical issues. These scholarly pursuits have resulted in valuable cross-cultural contributions and innovations in the field (e.g., Brooks \& Jean-Marie, 2007; Jean-Marie et al., 2009).

In this contribution we essentially and deliberately move away from localized notions of educational leadership as management and toward educational leadership as imperative for global human development and social betterment. This is done to incite reform of policy and practice for vital sustainable development. We propose big picture educational leadership that moves current thinking about the discipline and practice beyond effectiveness in teaching and learning and stakeholder satisfaction toward the future of this current generation including educational globalization. In this way, the intended outcome is for future development demanding a world-class educational leadership shift, and the future sustainability of educational effectiveness (Cheng, $2003,2007,2010)$. Furthermore, drawing on the work of Dimmock and Walker (2002) we argue that educational leadership involves the transformation of shared vision into reality, with an emphasis on cooperation (vs. competition), incorporating Indigenous ways of knowing or cultural intuition and rational thinking in problem solving, where power and influence are shared within a group. This approach to leadership, we maintain, flows from individual, to site, to region or state, to country, with direct links and associations with more global ways of conceptualizing educational leadership for rapidly changing contexts and the world. 


\section{Applied Critical Leadership: An Example of Research on Race, Racism, and Equity}

Applied Critical Leadership (ACL) is grounded in practices that are framed by social justice and educational equity wherein leadership results from both professional practice and leaders' embodied lived experiences (Santamaría, 2014; Santamaría \& Santamaría, 2012). Identification of this leadership approach emerged from several research studies of more than 11 Indigenous and culturally and linguistically diverse educational leaders in the US in a range of settings. ACL has interdisciplinary theoretical foundations including transformative leadership, critical pedagogy, and critical race theory (LadsonBillings, 1999; May \& Sleeter, 2010; Shields, 2010). In ACL, critical theories function to analyze asymmetrical power relations and inequities in educational contexts in order to "expose underlying assumptions that serve to conceal existing power relations" and the ways dominant members of societies construct "common sense" practices that result in long-term educational inequities for Indigenous learners, other learners of color, their families, and often their communities (Pihama, 1993, p. 57). The case studies featured in this study each portray leaders who practice ACL in US and NZ contexts.

Leaders like those featured, in that they also practice leadership through intersectional (e.g., race, gender, language, social class) frames of reference, have experienced educational injustices first hand or purposefully situated themselves outside of Whiteness (Haney Lopez, 1998). Therefore, the term 'people of color' is here used primarily as it is in the US to describe any person who is not White (e.g., African- American, Latino/a, Pasifika in NZ, non-White immigrants in European countries). The expression is meant to be inclusive among non-White groups, emphasizing common experiences of racism, discrimination, disproportionality, and similar inequitable treatment. 'People of color' is also used at times by members of the lesbian, gay, bisexual, transgender, questioning/queer (LGBTQ) community.

When educated professional people of color like those in this multiple case study have transcended a number of educational barriers, they may also be perceived as 'successful' in systems outside of their original/ ancestral indigenous or culturally informed 'ways of being.' These individuals may be far removed from or without memory of their Indigenous heritage due to a variety of colonial, neoliberal, or hegemonic factors (e.g., racism, war, forced relocation). Like participants in this inquiry, people of color, whether in the US or in other countries, have often experienced first hand, and often times more extremely as in the case of American Indian and 2nd language learners in the US schooling, institutional racism and gross inequities which may impact their leadership practice (e.g., Etxeberria, 2002; Harris et al., 2006; Richards, 1999).

Figure 1 below illustrates some experiential similarities and differences between educational leaders who are Indigenous and those who are leaders of color that may impact their leadership practice. American Indians and Alaska 
Natives, though Indigenous, when living in urban settings are often considered people of color in the US. This illustration demonstrates important distinctions between the groups as well as shared characteristics to further inform the premise of this contribution.

Indigenous Leaders

- Globally 'placed' under 'State-like' structures, incorporating national, social, and cultural characteristics alien to Indigenous 'ways of being' (Daes, 1996).

- Includes past or present forced relocation
Leaders of Color

- Primarily in US people who are not White (e.g., AfricanAmerican, Latino/a, Pasifika in NZ). The term is meant to be inclusive among nonWhite groups

- Can include past or present forced relocation, slavery, immigration, indentured work, poverty

Both groups share colonization, genocide, racism, brutality, linguicism, discrimination, disproportionality, and similar inequities. These shared oppressions form the basis of this work.

Figure 1. Indigenous leaders and leaders of color: Similarities and differences.

The participants in this study all identify as leaders of color who, though quite different on a variety of levels, counter educational injustice by way of practicing applied critical and culturally responsive leadership in their particular contexts. In their practice, these leaders move within and among individual, local, and global dimensions working to deliberately address and disrupt educational inequities associated with the politics of difference in their particular sociopolitical/ cultural/ geographic locations.

Because of the often binary and compartmentalized ways in which academics have traditionally presented educational research, divergent approaches for integrating the ideas, comparisons and similarities among the experiences of different groups are seldom portrayed. Complexity is described by the qualitatively minded as 'messy' and avoided by other research traditions. In our experience, the more complex the educational context, the more authentic, revealing layers, intersections, commonalities and differences among the 
practices of marginalized leaders emerging to support innovative ways of thinking about leadership in the present and for the future (Santamaría et al., 2014). For example, Table 1 below reflects ACL characteristics juxtaposed with Māori leadership roles as summarized by Tū Rangatira, a localized version of culturally responsive leadership in New Zealand (New Zealand Ministry of Education, 2010).

Table 1

Roles of Effective Māori Leaders and Characteristics of Applied Critical Leadership (ACL)

\section{Tū Rangatira -Example of Key Roles in Indigenous Māori Leadership Context}

The Advocate: to promote the development and implementation of strategies, plans and policies to realize learners' potential and their educational success as Māori.

The Networker: to network, broker and facilitate relationships that contribute towards achieving school goals.

The Guardian: to protect and nurture a caring environment where people and ideas are valued; health, safety and well-being are enhanced; and relationships are strong.

The Manager: to ensure the effective and efficient management of people, environments and education to transform teaching and learning communities.

The Teacher and Learner: to use reciprocal learning and exemplary modelling of innovation that leads to the effective creation, development and delivery of high-quality authentic learning contexts and practice.

\section{ACL Characteristics and Individual (I), Local (L), or Global (G) Dimension Employed}

Leaders' willingness to initiate and engage in critical conversations--often regarding race, language, culture, difference, access, and/or educational equity $(I, L)$.

Leaders' ability to choose or the assumption of a CRT lens for decisionmaking (I).

Leaders' use of consensus as the preferred strategy for decision-making $(\mathrm{I}, \mathrm{L})$.

Leaders feeling the need to build trust when working with mainstream constituents or partners or others who do not share an affinity toward issues related to educational equity $(I, L, G)$.

Leaders feeling the need to honor all members of their constituencies $(I, L)$.

Leaders making empirical or researchbased contributions to educational contexts, adding authentic research based information to academic discourse regarding educational equity issues $(I, L, G)$. 
The Worker: to be seen to be 'leading by doing,' upholding collegial practices that build capability in others in pursuit of the goals of the school.

The Visionary: to have innovative and visionary leadership to equip learners with the knowledge, skills and values to succeed in the 21st century as Māori and as citizens of the world.
Leading by example to meet unresolved educational needs or challenges (I, L, G).

Leaders describing themselves as transformative, servant leaders who work ultimately to serve the greater $\operatorname{good}(I, L, G)$.

The table illustrates ways in which ACL characteristics found in leaders of color in the US and the notion of individual (I), local (L), global (G) leadership practice can be realized in an Indigenous global context. It demonstrates common ground shared that can be addressed with identifiable leadership practices for sustainability and provides evidence that key players who may be able to inform educational leadership practices for change may have been historically absent from important policy making, program planning, and reform platforms, working groups, etc. in the past. This representation lays the foundation for a closer look at ways in which cultural responsive leadership can counteract educational injustice and promote sustainable change.

\section{Methodological Approach}

The multiple case study presented in this article was informed by prior research investigations undertaken with members of the communities being considered. These include a comparative study of Indigenous leadership practices and practices of leaders of color in urban school settings in NZ and the US (Santamaría et al., 2014), studies of the leadership practices of leaders of color promoting social justice and equity (Santamaría, 2014; Santamaría \& JeanMarie, 2014; Santamaría \& Santamaría, 2012), and an inquiry to better understand the leadership practices of Māori and Pasifika principals in NZ (Santamaría, et al., 2014). In this paper, the work serves to emphasize detailed contextual analysis of a limited number of events, conditions, and relationships related to counteracting educational injustice with applied critical leadership as an expression of culturally responsive leadership to promote lasting change (Yin, 1996). Further, a multiple case study approach was employed to provide in-depth profiles for participants, multifaceted enough to create narrative counter-stories of their leadership practices to "counter deficit storytelling" (Solórzano \& Yosso, 2002 , p. 23). In this way, counter-stories serve to expose, analyze, and challenge mainstream majority stories steeped in privilege in order to "challenge the dominant discourse" on difference (Solórzano \& Yosso, 2002, p. 32). 
By integrating complementary critical theory methodology, authors draw from data collected over the course of three years in the US and NZ based on common experiences and shared oppressions of leaders of color in both countries (i.e., interviews, surveys, observations, documents written by participants). Data were analyzed using constant comparative methods in order to construct cumulative representative narrative accounts or counter-stories based on the most frequent themes that came through in the data (Glaser, 1965; Solórzano \& Yosso, 2002). These accounts serve to provide a record of the ways in which the leaders at a variety of levels (e.g., early childhood, primary, middle years, secondary, tertiary) enact leadership.

Perspectives featured include those of men and women who are either people of color, Indigenous people, or those who decidedly race themselves outside of Whiteness and work to benefit systemically underserved learners. The accounts featured were pulled together and interwoven to construct counterstories that further serve an ethical purpose to protect the anonymity of the participants while telling their collective stories. Finally through the critical approach undertaken, authors draw on and acknowledge our own intersectional identities as African, Indigenous, and Mexican American heterosexual woman and man; participating in and producing research and leadership practices in New Zealand to promote social justice, equity, and subaltern ways of conceptualizing leadership for diversity.

\section{Findings}

Following independent and collaborative data analyses, three distinct counter narratives were developed. These counter-stories derived from 16 US participants and six NZ participants are presented as the experiences of three leaders. Following the narratives, the discussion section will unpack emergent themes in relation to the research questions posed.

\section{Julian}

During his interview for his position, Julian, the Black Latino principal at Sunrise primary school in Southern California was addressed by a school board member in Spanish about the ways in which he might increase communication with the parents of English language learners from Mexico and other Latino community members who would look to him for direct communication during his leadership tenure at the school. Having spent his childhood under the care of his Spanish language dominant abuela (grandmother), who lived a block away from his family home; Julian answered the interview committee member in near fluent Spanish. His plan was to provide a fully bilingual information and communication platform to parents and community members, as well as to provide interpreters as necessary to ensure that as many school stakeholders as possible knew the 
goings on at the community-centered school. In his response, remembering his abuela's distance from his schooling experience, Julian included a detailed strategy for increasing meaningful participation of Latino Spanish speaking families, African-American families, as well as other parents and community groups that he understood from personal and professional experience and previous research were frequently absent from school functions. He had a definitive plan for including these constituents' voices in consensus-oriented decision making for the school, in response to the majority of the students at the school and their families who were Latino or otherwise people of color. During Julian's thorough, confident response the interview committee exchanged nervous smiles with each other while taking copious notes. He told the committee that he considered himself to be a leader most when he was working alongside and together with teachers, staff, parents, and family members providing an example for a community response to solving the needs of the school (e.g., academic achievement inequities, access). This leadership by example, he explained, would pull others in and eventually lighten the load for everyone. Although he was eventually hired, there were times when Julian wasn't confident that the school board or English dominant parents were happy with the growing presence and participation of Latino parents, many who proudly identified as Chican@, nor the diverse community members in and around the school that had incrementally increased as a result of his being hired. He felt he needed to work hard to build trust with his board, peers, and monolingual members of the community who were not Latino or people of color.

\section{Ngaire}

As a Māori woman indigenous to Aotearoa,New Zealand, and as the principal of Pearson Urban Primary school located on the city fringe, Ngaire often felt disconnected from other educational leaders in the country and the world when thinking about ways to improve her leadership practice. She facilitated and mentored a network of Māori principals in her region to stay connected and to comfortably engage in conversations about ethnicity, race, language, culture, and access with other Indigenous leaders in similar situations. In Ngaire's geopolitical context there were a disproportionate number of Māori principals as compared to the proportion of Māori learners in schools. The Ministry of Education was aware of this disparity and was working on plans to recruit, train, or sustain their leadership practices at nearby universities. This NZ predicament is similar to that of leaders of color in the US relative to a growing culturally and linguistically diverse student population. In the recent past, the leadership guidelines provided by the NZ Ministry of Education originated from Pākehā (NZ European) ideologies, theories, and world views. These resulted in mismatches compared to notions of Māori learners experiencing school success as Māori, and were virtually absent of cultural and linguistic responsivity that would support other 'diverse' and immigrant learners' academic achievement. Ngaire was cognizant of, and led her teachers and staff toward, culturally responsive 
teaching practices to meet the needs of Māori students and their whānau (families), as well as their tribal affiliations. She also advocated for inclusive diversity as she simultaneously considered the multicultural nature of the school that additionally served Pasifika learners from Samoa, Niue, Fiji, and other nearby islands as well as those immigrant students and families from countries such as Switzerland, Italy, Australia, China, Morocco and the US. Ngaire led in this way to counter the academic and often socio-economic disparities separating the Indigenous and diverse learners at her school from their Pākehā counterparts attending school in wealthier areas of the city. The academic disparities experienced by her students were similar to the gaps Julian faced with his students while leading the staff at his school in California.

\section{Charlene}

Charlene was the former ESL teacher at Glen Mountain Elementary where she taught the 4th grade for two years prior to becoming the assistant principal at a primary school in Kentucky three years ago. Her school was located in a city that welcomed both refugees and visiting university scholars from around the world, in response to the booming population of English learners (ELs). Charlene, a new educational leader, was distressed that ELs appeared to be an annoyance to their mainstream classroom teachers. Leading through a critical theory lens, she said, "The teachers are good, but they are not equipped to create learning environments that include children who speak another language, come from another country, have uneducated parents, qualify for free/reduced lunch, etc." These teachers did well with including children with 'special needs' in the sense that they differentiated for a child with autism or physical disabilities, but it broke Charlene's heart when they were unwilling or unable to differentiate for Trevonte, an African-American child without a learning disability who disrupted class and refused to do work (and had been in numerous foster homes, currently being raised by a grandmother who worked two jobs); or for Maria, a bilingual Latina who never returned homework and failed miserably on most tests. English learners were not progressing the way they could at Glen Mountain Elementary (especially since it had won an award as a Blue Ribbon school). Charlene felt the school could do better. A White woman, committed to addressing inequities based on ethnicity, language, class and gender, and who had incidentally adopted an African American toddler, Charlene was in the process of approaching her principal with some ideas for Professional Development on ways to meet the needs of students like Trevonte and Maria. She had tried to share the professional development she had received in California as part of her teacher preparation with regard to culturally responsive pedagogical practices, but wanted to look into professional development programs and presenters who could come in and shift critical paradigms with her staff. Her principal said he wanted to invest in hiring national presenters to come in (again) and present Sheltered Instruction Observation Protocol (SIOP) to the staff, but most of these teachers already had that training and still pushed ELs 
out into ESL settings without including them in the regular mainstream classroom. Some children were spending two hours a day doing this. Like Julian and Ngaire, Charlene was ready to engage more radical and systemic ways to address and interrupt the educational inequities at her school.

In their own way, each leader featured demonstrated ways to counter injustice by employing culturally responsive approaches. A deeper discussion of the findings yields important trends that came through in the data as organized by the research questions posed.

\section{Discussion and Implications}

Research findings from this inquiry suggest that Indigenous leaders and those with Indigenous world-views may be key players who practice ACL as culturally responsive leadership contributing to sustainable change. Data analyzed suggested that Western-centered leadership practices based on dominant discourses and histories of colonization have missed the mark when it comes to leadership in educational settings (Santamaría \& Santamaría, 2012).

\section{What We Can Learn from Indigenous Leaders}

The first peoples of every colonized nation have deep leadership traditions and roots that served to inform educational practices of their communities prior to the arrival of those who 'discovered' their lands (Pihama, 1993). Today, Indigenous leaders like Ngaire are those who come from communities, peoples, and nations that have a historical continuity with pre-invasion and pre-colonial societies developed on their territories, distinct from other sectors of the societies now prevailing in those territories or parts of them. Ngaire and other Indigenous leaders often form non-dominant sectors of society that are determined to preserve, develop and transmit to future generations ancestral territories, ethnic identity, as a basis of continued existence as peoples in accordance with their own cultural patterns, social institutions and legal systems (Cobo, 1986). This occurs even if Indigenous peoples are formally placed under a State structure, incorporating national, social, and cultural characteristics alien to Indigenous ways of being (Daes, 1996).

As a result, when Indigenous leaders are responsible for leading schools that serve Indigenous students, they are able to support their communities, teachers, and staff in incorporating essential elements of their language, culture, and ways of learning into the education (Bishop et al., 2009). Ngaire led using Tū Rangatira, for example, to support all learners in her school, specifically Indigenous and Pasifika, toward academic success, human development and well-being including Māori success as Māori (Durie, 2006). From individual to 
local and global practice, her leadership was innovative and could serve to inform others.

\section{Leaders of Color}

Julian and other leaders of color in the US spoke of remembering educational injustices throughout their schooling experiences. These ranged from being placed in the back of the room with other children of color, being assessed for language and special education services, sitting outside of the classroom for 'disrupting' others and being 'placed' in remedial classes in secondary school. These experiences, Julian said, as similarly shared by other critical leaders, had a direct impact on what he studied at the university and what he eventually chose to do as a profession. He felt it was his responsibility to teach and lead in such a way as to enable students from traditionally underserved backgrounds, and their families, to participate and succeed in schools in the US (Santamaría \& Santamaría, 2012). Julian and Ngaire exemplify leaders who are of color and Indigenous, respectively. They each express educational leadership practices that draw directly from their identities and express elements of their culture and language (Lomotey, 1987; Tillman, 2008).

\section{Leaders Who Are Not Indigenous and White Who Practice ACL}

As demonstrated by Charlene in this article and by other examples of scholars who work in the area of leadership for social justice and educational equity (e.g., Brooks, 2008; Normore, 2008), there are leaders who may also be White and mainly of European descent who choose to assume a CRT lens or race themselves outside of Whiteness, thereby putting privilege aside or using their inherent privilege to practice ACL. Like Charlene, these leaders tend to lead in culturally, linguistically, ethnically and socio-economically diverse situations out of responsibility vs. guilt. This we know to be true as we are familiar with Charlene and all of these scholars in both personal and professional settings. These leaders, some who 'race themselves outside of Whiteness,' have the luxury of 'choosing' whether or not they will take up arms and fight alongside Indigenous and leaders of color toward leadership for social justice and equity (Haney Lopez, 1998). They 'choose' frames of reference through which to lead, whether those frames are Indigenous or those of people of color or some other difference associated with oppression. Research indicated that these leaders' commitment is clear and often based on a critical moment, realization, experience or series of experiences that they are able to identify, which serves to fuel the choices they make and the fight with which they engage in their personal and professional leadership paths. These individuals are considered allies in efforts for social justice and educational equity. Their valuable work is acknowledged and appreciated, as these leaders' practices 
intersect with the work of Indigenous and leaders of color, but each type of practitioner's ways of approaching issues are unique and different.

\section{Intersectionality as Innovation}

As the world advances, shifts, and changes, educational leadership practices need to advance as well. Inquiry findings suggest there are ways in which Indigenous leaders, leaders of color, and leaders who purposefully 'choose' to align their practices toward cultural responsivity can be recognized as distinctly different, yet working toward the same shared goals based on common challenges. Their collective leadership practice can yield different results for sustainable oppression-responsive practices now and in the future.

We maintain, from the research undertaken, that the intersectionality as manifested in leadership practices in diverse contexts is not merely an observation but a necessity if educational scholars and leaders are to keep up with the needs of education in the US and the world. We are at a point in terms of preparation, practice, and policy wherein race, ethnicity, gender, language, social class, access, and global position need to be gravely considered (Young \& Brooks, 2008). Educational stakeholders, practitioners, leaders, managers, and academics need to assess, pool, and redistribute resources according to critical need. Research and development needs to increasingly focus on the assembly of local and global summits, think tanks, and similar cross-cultural international efforts to improve the state of education. Research teams need to be assembled to design studies, develop theories, and document this new and emergent knowledge stream (Santamaría, in press). We assert and acknowledge that this is unchartered territory but are confident there are others ready to embark on this movement of educational advances to meet the needs of the more highly evolved and complex learners of today in schooling systems that are in a rapid state of flux.

\section{Implications for Educational Leadership Preparation, Policy, and Reform}

If educators and educational stakeholders are to advance and improve the ways in which they provide education for children who constitute the bulk of global achievement gaps, leaders at the 'top' need to be as compassionate, generous, and responsible as possible. Knowledge and value of multiple perspectives can usher the promotion of every kind of leader being valued for the unique, different, and specialized ways of knowing, access, and resources each brings to the table (Mansfield, 2014). At the same time, our research findings suggest that cultural, ethnic, racial, gender, and class differences need to be acknowledged, celebrated, contemplated, and understood in order for similarities and shared oppressions (which will ultimately fuel the work) to be embraced 
(Bogotch, 2002; Jean-Marie, 2008). This we believe will result in the change and sustainability inherent in relationships to further foster desirable change.

From our research findings as exemplified in Ngaire's, Julian's, and Charlene's counter-stories, we have learned that leaders can counteract educational injustice through applied critical leadership (ACL) by way of sustainable culturally responsive leadership in a number of ways.

First, the practice comes out of the people wherein it is situated. Some of the ways we can follow their leadership example are by:

1. Entering into leadership spaces with informed knowledge or willingness to learn the socio-political, cultural, and linguistic context surrounding the learning environment.

2. Practicing humility, which includes deferring to and seeking participation and accountability with established community leadership (e.g., elders, retirees, community leaders).

3. Being present to and providing for a variety of authentic interactions (e.g., face to face, school site, community spaces, spiritual meeting spaces, constituents' homes).

4. Recognizing biases while tapping positive aspects of our own identity from which to draw to lead with authenticity and integrity.

5. Practicing decision making within locally responsive parameters, physical spaces, and cultural conditions to complement (vs. counter) cultural norms.

6. Holistically embodying leadership as an extension of the expression of whole self.

7. Connecting deeply to the community by grounding and sharing leadership practice in ways that ensure its sustainability and key role in supporting improvement and positive educational change.

Secondly, ACL is individual, with leadership coming directly out of the cultural or identity-based strengths of the person in charge, strengths that are recognizable and shared with the constituents. It is also deeply locally responsive. The leaders who practice $A C L$ see themselves as local, regional, and global citizens. Finally, ACL is sustainable because it is not isolated and unattached. Even those leaders who are not as connected to international leadership practices are attached to their communities and peers. These leaders seek out connections with others with whom they can relate, collaborate, or learn. They are attracted to or seek professional development opportunities and postgraduate education in an effort to connect to others on their professional and sometimes personal interest - consistently for the betterment of the students in the communities they serve. 


\section{Conclusion}

This contribution has implications that are both challenging and promising. We maintain that when aspiring and practicing educational leaders, teachers, stakeholders, and those involved in policy authorship think about global educational leadership, an open-minded approach to create educational research spaces for subaltern knowledge to be spoken and heard is needed. We need to engage in this way in order to respond to 21 st century and future-focused research questions and evolving educational practices. There has been mention of inclusivity and inviting 'others' to various 'tables,' wherein tokenism reigns supreme in culturally and linguistically diverse settings. In these cases, consensus can come across as bullying wherein the voices of the representative minority are drowned out, yet decision makers could say the marginalized voice was 'at the table' when the decision was made. Different, more qualitative inclusion of historically silenced populations is necessary if appropriate and responsive ways of problem solving, education, and leadership in these contexts are to be genuinely sought.

We are suggesting an exponential leap beyond tokenism including the need to increasingly consider notions of global educational "interculturality" (Walsh, 2010), incorporating intellectual, scholarly, academic, and practical 'space' to generate new thinking about social, political, ethical and epistemic considerations of everyday life. Previous research suggests that when we link knowledge with history, perspectives, worldview, and logic of historically silenced and oppressed social subjects, dominant knowledge and ways of knowing are transformed toward the positive (see Santamaría, 2014).

In this inquiry we deliberately depart from transformative leadership, which includes more progressive versions of previously understood and traditional notions of educational leadership (Shields, 2010). We do so by acknowledging that (a) educational leadership is an interdisciplinary, complex, and multi-pronged process, wherein (b) educational partners need to develop participatory alterNative leadership practices that adhere to critical democracy (e.g., from individual, to local, to national, to global). We also acknowledge that educational leadership, as a discipline, (c) needs to deliberately delink from notions of leadership as management. Finally, educational leaders need to (d) use known, new, and developing tools to foster communication addressing educational issues for marginalized and all learners toward increased global intelligence. It is our intention that this multiple case study benefits aspiring and practicing leaders in educational settings in the US and our global community whether they are teachers, policymakers, or students. We have deliberately pushed existing theory in several new directions and extended current thinking about educational leadership for diversity by incorporating Indigenous perspectives and world views, as well as the perspectives of leaders of color, filling the void where these voices are not present and, thus, bringing a new perspective to current literature. There is much to be done with regard to additional research on this topic with which we are currently engaged. We invite others to join us as we answer this 
call to scholarship and practice for the good of our own children and all learners who stand to benefit in the world.

\section{References}

Bishop, R. (1996). Collaborative research stories: Whakawhanaungatanga. Palmerston North, New Zealand: Dunmore Print Company.

Bishop, R., Berryman, M., Cavanagh, T., \& Teddy, L. (2009). Te kotahitanga: Addressing educational disparities facing Māori students in New Zealand. Teaching and Teacher Education, 25(5), 734-742.

Bogotch, I. E. (2002). Educational leadership and social justice: Practice into theory. Journal of School Leadership, 12(2), 138-156.

Brooks, J. S. (2008). Introduction part one: What can social justice educators learn from the social sciences? In I. Bogotch, F. Beachum, J. Blount, J. Brooks, \& F. English (Eds.), Radicalizing educational leadership: Dimensions of social justice (pp. 1-10). Rotterdam, The Netherlands: Sense Publishers.

Brooks, J. S., \& Jean-Marie, G. (2007). Black leadership, White leadership: Race and race relations in an urban high school. Journal of Educational Administration, 45(6), 756-768.

Brooks, J. S., \& Normore, A. H. (2010). Educational leadership and globalization: Literacy for a glocal perspective. Educational Policy, 24(1), 52-82.

Cheng, Y. C. (2003). School leadership and three waves of education reforms. Cambridge Journal of Education, 33(3), 417-439.

Cheng, Y. C. (2007). Future developments of educational research in the AsiaPacific Region: Paradigm shifts, reforms, and practice. Educational Research for Policy and Practice, 6(2), 71-85.

Cheng, Y. C. (2010). Multiple thinking and creativity in school leadership: A new paradigm for sustainable development. In S. Huber (Ed.), School leadership: International perspectives (pp. 181-210). Dordrecht, The Netherlands: Springer.

Cobo, J. R. M. (1986). The study of the problem of discrimination against Indigenous populations (Conclusions). New York: United Nations, UN Document E/CN.4/Sub.2/1986/7/Add.4

Daes, E-I. A. (1996). On the concept of an 'Indigenous People'. Working Paper by the Chairperson, Mrs. Erica-Irene Daes. New York: United Nations, Economic and Social Council, UN Document E/CN.4/Sub.3/AC.4/1996/2.

Dimmock, C., \& Walker, A. (2002). School leadership in context: Societal and organisational cultures. The Principles and Practice of Educational Management, 70-85. 
Duncan-Andrade, J. M. (2009). Note to educators: Hope required when growing roses in concrete. Harvard Educational Review, 79(2), 181-194.

Durie, M. (2006). Māori education 2026. Address to the Post Primary Teachers' Association Conference. Palmerston North, New Zealand: Massey University.

Etxeberria, F. (2002). Education and Roma children in the Basque region of Spain. Intercultural Education, 13(3), 291-304.

Glaser, B. G. (1965). The constant comparative method of qualitative analysis. Social Problems, 12, 436-445.

Gooden, M. A., \& Dantley, M. (2012). Centering race in a framework for leadership preparation. Journal of Research on Leadership Education, 7(2), 237-253.

Haney Lopez, I. (1998). White by law: The legal construction of race. New York: New York University Press.

Hargreaves, A., \& Fink, D. (2004). The seven principles of sustainable leadership. Educational Leadership, 61(7), 8-13.

Harris, R., Tobias, M., Jeffreys, M., Waldegrave, K., Karlsen, S., \& Nazroo, J. (2006). Racism and health: The relationship between experience of racial discrimination and health in New Zealand. Social Science \& Medicine, 63(6), 1428-1441.

Horsford, S. D. (2010). Mixed feelings about mixed schools: Superintendents on the complex legacy of school desegregation. Educational Administration Quarterly, 46(3), 287-321.

Horsford, S. D. (2011). Learning in a burning house: Educational inequality, ideology, and (dis) integration. New York: Teachers College Press.

Jean-Marie, G. (2008). Leadership for social justice: An agenda for 21st century schools. The Educational Forum, 72(4), 340-54.

Jean-Marie, G., Normore, A. H., \& Brooks, J. S. (2009). Leadership for social justice: Preparing 21st century school leaders for a new social order. Journal of Research on Leadership Education, 4(1), 1-31.

Khalifa, M. (2012). A re-new-ed paradigm in successful urban school leadership principal as community leader. Educational Administration Quarterly (EAQ), 48(3), 424-467.

Kirsch, I., de Jong, J., Lafontaine, D., McQueen, J., Mendelovits, J., \& Monseur, C. (Eds.). (2002). PISA reading for change: Performance and engagement across countries. Results from PISA 2000. Paris: Organization for Economic Co-operation and Development.

Ladson-Billings, G. (1999). Preparing teachers for diverse student populations: A critical race theory perspective. Review of Research in Education, 24, 211-247. 
Leithwood, K. A., \& Poplin, M. S. (1992). The move toward transformational leadership. Educational Leadership, 49(5), 8-12.

Lomotey, K. (1987). Black principals for Black students: Some preliminary observations. Urban Education, 22(2), 173-81.

Mansfield, K. C. (2014). Creating smooth spaces in striated places: Toward a global theory for examining social justice leadership in schools. In I. Bogotch \& C. M. Shields (Eds.) International Handbook of Educational Leadership and Social (In) Justice (pp. 37-50). Dordrecht, The Netherlands: Springer.

Maslow, A. H. (1943). A theory of human motivation. Psychological Review, $50(4), 370$.

May, S., \& Sleeter, C. E. (Eds.). (2010). Critical multiculturalism: Theory and praxis. New York: Routledge.

Moll, L. C., Amanti, C., Neff, D., \& Gonzalez, N. (1992). Funds of knowledge for teaching: Using a qualitative approach to connect homes and classrooms. Theory Into Practice, 31(2), 132-141.

Murakami-Ramalho, E., Nuñez, A. M., \& Cuero, K. K. (2010). Latin@ advocacy in the hyphen: Faculty identity and commitment in a Hispanic-serving institution. International Journal of Qualitative Studies in Education, 23(6), 699-717.

New Zealand Ministry of Education. (2010). Tū rangatira: Māori medium educational leadership. Wellington, New Zealand: New Zealand Ministry of Education.

Normore, A. H. (Ed.). (2008). Leadership for social justice: Promoting equity and excellence through inquiry and reflective practice. Charlotte, NC: Information Age Publishing.

Pihama, L. (1993). Tungia te ururua, kia tupu whakaritorito te tupu o te harakeke: A critical analysis of parents as first teachers. (Unpublished master's thesis dissertation). New Zealand: The University of Auckland.

Richards, T. L. (1999). Dancing on our bones: New Zealand, South Africa, rugby and racism. Wellington, NZ: Bridget Williams Books.

Santamaría, L. J. (in press). Culturally responsive educational leadership in cross-cultural international contexts. In N. D. Erbe \& A. H. Normore (Eds.), Cross-cultural collaboration and leadership in modern organizations (pp. xX-Xx). Hershey, Pennsylvania: IGI Global.

Santamaría, L. J. (2014) Critical change for the greater good: Multicultural dimensions of educational leadership toward social justice and educational equity. Education Administration Quarterly (EAQ), 50(3), 347391.

Santamaría, L. J., \& Jean-Marie, G. (2014). Cross-cultural dimensions of applied, critical, and transformational leadership: Women principals advancing 
social justice and educational equity. Cambridge Educational Journal, 44(3), 333-360.

Santamaría, L. J., \& Santamaría, A. P. (2012). Applied critical leadership in education: Choosing change. New York, NY: Routledge Books.

Santamaría, L. J., Santamaría, A. P., Webber, M., \& Pearson, H. (2014). Indigenous urban school leadership (IUSL): A critical cross-cultural comparative analysis of educational leaders in New Zealand and the United States. Canadian and International Education, 43(1), 1-21.

Shields, C. M. (2010). Transformative leadership: Working toward equity in diverse contexts. Education Administration Quarterly (EAQ), 46(4), 558589.

Solórzano, D. G., \& Yosso, T. J. (2002). Critical race methodology: Counterstorytelling as an analytical framework for education research. Qualitative Inquiry, 8(1), 23-44.

Tillman, L. C. (2008). The scholarship of Dr. Asa G. Hilliard, III: Implications for Black principal leadership. Review of Educational Research, 78(3), 589607.

Theoharis, G. (2007). Social justice educational leaders and resistance: Toward a theory of social justice leadership. Educational Administration Quarterly (EAQ), 43(2), 221-258.

Walsh, C. (2010). De-coloniality, decolonial thinking and doing in the Andes: A conversation by Walther Mignolo with Catherine Walsh. Reartikulacija, 10, 11, 12, 13.

Yin, R. K. (1996). Case study research-Design and methods. Applied Social Research Method Series (5), London: Sage.

Young, M. D., \& Brooks, J. S. (2008). Supporting graduate students of color in educational administration preparation programs: Faculty perspectives on best practices, possibilities, and problems. Educational Administration Quarterly (EAQ), 44(3), 391-423. 